\title{
É POSSÍVEL FAZER UMA ETNOGRAFIA DAS ESCOLAS? 0 CASO DA FRONTEIRA AMAZÔNICA BRASIL-COLÔMBIA E DOS POVOS TICUNA E MURUI-MUINA
}

\author{
MAURICIO CAVIEDES ${ }^{1}$ \\ Pontificia Universidad Javeriana
}

\begin{abstract}
RESUMO: Neste artigo, explica-se o método de análise da linguagem a partir de dados recolhidos por meio da observação etnográfica nas escolas indígenas dentro do projeto de pesquisa de pós-doutorado "A educação da mulher indígena: contradições da identidade nas escolas indígenas Murui-Muina e Tikuna, na Amazônia da Colômbia e do Brasil", que faz parte do Núcleo de Antropologia das Sociedades Indígenas e Tradicionais do Programa de PósGraduação em Antropologia Social da UFRGS. O artigo utiliza entrevistas com professores e professoras indígenas para entender, por meio da análise da linguagem, as experiências que influenciam a identidade indígena e a sua relação com a identidade de gênero no contexto do ensino escolar. Baseado nessas entrevistas, o artigo sugere desafios para futuras pesquisas sobre a educação escolar indígena na Amazônia. Com o intuito de refletir sobre a desigualdade entre conhecimentos universais e indígenas, o artigo explica primeiro os antecedentes antropológicos da análise da linguagem; a seguir, apresenta a influência da linguagem na identidade étnica e, finalmente, descreve a linguagem dos professores para entender a influência da educação escolar na experiência de ser indígena e apresenta os desafios futuros nesse campo.
\end{abstract}

PALAVRAS-CHAVE: povos Indigenas; Etnologia; Amazônia; Colômbia; Brasil; educação indigena.

\begin{abstract}
This article explains the ethnographic use of language analysis through collected data in indigenous schools during fieldwork, as part of the post-doctoral research project entitled "The education of indigenous women: identity contradictions in the schools of the Murui Muina and Ticuna people in the Amazonas River Basin, in the border between Colombia and Brasil", within the Núcleo de Antropologia das Sociedades Indígenas e Tradicionais, PPGAS-UFRGS. The article presents interviews with indigenous school's teachers in order to explain experiences that determine indigenous identity and its relation to gender identity, based in an ethnographical analysis of language within the context of indigenous schools. The articles suggests challenges for future research on indigenous school education in the Amazonas region. In order to understand the inequality between indigenous and "universal" forms of knowledge, the article commences by summarizing the background of language analysis in anthropology; next, it explains the relation between ethnic and gender identity and language; finally, it describes the
\end{abstract}

\footnotetext{
${ }^{1}$ Mauricio Caviedes é formado em antropologia, Mestre em antropologia e Doutor em Historia pela Universidad Nacional de Colômbia. Foi pós-doutorando do PPGAS-UFRGS (2015-2017) e atua como professor Associado do departamento de Antropologia da Pontificia Universidad Javeriana (Bogotá). Faz parte do Grupo de Trabajo de Autonomías Indígenas organizado por PNUD-Bolivia. E-mail: mauriciocaviedes2009@gmail.com .
} 
language used by indigenous teachers in order to understand how schools shape indigenous experiences, presenting, thus, the main challenges for future research.

KEYWORDS: indigenous People; Ethnology; Amazonas; Colombia; Brasil; indigenous education.

\section{Introdução}

Este artigo apresenta uma justificativa sobre o uso da metodologia de análise da linguagem na pesquisa sobre educação indígena do projeto de pós-doutorado intitulado "A educação da mulher indígena: contradições da identidade nas escolas indígenas Murui-Muina e Tikuna, na Amazônia da Colômbia e do Brasil", dentro do Núcleo de Antropologia das Sociedades Indígenas e Tradicionais, do PPGAS-UFRGS. A pesquisa apresentada aqui foi realizada nas aldeias indígenas do resguardo indígena Ticuna Uitoto Kilómetro 11 (Leticia, Colômbia), San Antonio (Leticia, Colômbia) e nas comunidades indígenas Umariaçu I e II (Tabatinga - AM, Brasil). O artigo explica a análise da informação etnográfica coletada nas escolas indígenas na fronteira do Brasil com a Colômbia entre professores e professoras, crianças e autoridades indígenas. Acentua-se neste artigo a importância do estudo antropológico da linguagem utilizada na escola pelos professores indígenas para se afastarem, ou aproximarem, das identidades indígenas. A partir deste estudo, pretende-se apresentar os principais desafios no estudo da educação escolar indígena.

Para facilitar a compreensão dessas ideias e do uso da etnografia da linguagem nesta pesquisa, o artigo explica primeiro por que o estudo etnográfico da linguagem, mesmo que não seja novo, ainda não foi suficientemente aproveitado na antropologia da educação indígena. A seguir, define-se a relação entre identidade e linguagem, com o propósito de explicar a relevância desta última no estudo da educação indígena. Finalmente, o artigo descreve a relação entre a linguagem dos professores e a educação escolar a partir dos dados coletados. Com isso, sugere alguns desafios para futuras pesquisas. 


\section{O estudo etnográfico da linguagem na educação}

Por que a linguagem utilizada nas escolas da fronteira amazônica é o foco da observação etnográfica desta pesquisa? A importância dos estudos críticos do discurso e da linguagem reflete-se em tantas pesquisas atuais que não parece necessário defender o seu uso. Vários trabalhos utilizam a análise do discurso para explicar as dificuldades da educação intercultural na Colômbia (CASTILLO e ROJAS, 2005). Outros trabalhos estudam as dificuldades na representação dos povos indígenas nas escolas no Brasil (GOBBI, 2012). Existem também autores que estudam como as políticas públicas entendem conceitos como "interculturalidade" (NASCIMENTO, 2014), ou as diferenças entre conceitos indígenas e antropológicos de educação (TASSINARI, 2012). Entretanto, neste artigo argumenta-se, em concordância com as ideias de Hymes, que faltam estudos para ligar contextos históricos, políticos e econômicos de forma comparada à dinâmica das escolas indígenas. Esse estudo comparado deve ajudar na busca por instrumentos educacionais que reduzam as hierarquias dos conhecimentos e, portanto, criem espaços de debate entre os conhecimentos indígenas e os conhecimentos chamados "universais" (HYMES, 2004).

O linguista e antropólogo americano Dell Hymes afirma que os estudos etnográficos sobre a educação com frequência erram na forma de estudar as escolas, porque as analisam como uma unidade. No entanto, a linguagem, as instituições e as sociedades estão envolvidas em relações políticas e históricas. Em consequência, a aula deve ser estudada enquanto parte de um contexto cultural, político, social e histórico; isso, além de permitir comparações e classificações nas escolas, continua Hymes, evidencia relações de desigualdade: algumas classes sociais aproveitam melhor a escola do que outras porque as instituições dessas classes compartilham a linguagem da escola. Por essa razão, a linguagem da escola não pode ser estudada fora das relações das escolas com a estrutura histórica, cultural, política e de classe que a rodeia.

Um dos exemplos que Hymes apresenta como evidência da sua hipótese é o fato de serem desconsideradas as distintas formas que 
assume a linguagem "nacional" entre os indígenas ou migrantes nos Estados Unidos nas políticas de educação bilíngue e intercultural. Hymes tenta demonstrar que, nas escolas interculturais, as políticas só levam em conta a presença do inglês e da língua "nativa", sem aceitar que migrantes mexicanos e seus filhos, e também indígenas americanos e suas crianças, falem um "inglês fora do padrão" (non standard english). Nas escolas, o inglês fora do padrão é castigado por ser considerado errado e associado a classes sociais percebidas como inferiores. No entanto, segundo Hymes, as crianças afroamericanas apresentam um inglês com uma estrutura gramatical própria. Em outras palavras, as crianças são levadas a abandonar não somente a língua indígena, mas também as variantes indígenas do português e do espanhol.

Se as hipóteses de Hymes forem aceitas, é possível perguntar se a hierarquia de classe criada pela escola não é uma hierarquia cultural. Em consequência, o objetivo de Hymes é fazer a etnografia dessas desigualdades, com o intuito de reduzi-las (HYMES, 2004).

Esta pesquisa compartilha esse propósito: buscar formas de reduzir as desigualdades de classe, formuladas como desigualdades culturais, étnicas e de gênero, produzidas pela relação entre as escolas e a história dos seus países. Nessa perspectiva, incorpora-se também a importância de a pesquisa ser comparada, em algum momento. No entanto, é importante afirmar que este esforço investigativo não supõe ter conseguido o objetivo de Hymes (fazer uma classificação antropológica das escolas indígenas): sugere apenas caminhos para continuar esse processo na literatura antropológica da América Latina.

Para entender o uso da análise da linguagem no estudo das escolas indígenas da fronteira entre o Brasil e a Colômbia, é preciso explicar o que nesta pesquisa é chamado de "etnografia das escolas" e "análise da linguagem". Assim, apresentam-se aqui esses termos e a forma como eles foram utilizados durante a pesquisa.

É importante estabelecer que o pesquisador que apresenta os resultados desta investigação não é linguista, nem tenta fazer linguística: é somente um antropólogo interessado no lugar da linguagem nas relações sociais, nas hierarquias culturais e no contexto histórico da educação dos povos indígenas. É a partir desse ponto de vista que a linguagem é aqui analisada, e não a partir da área da Linguística, da 
Fonologia ou da Gramática. No entanto, esta pesquisa é apresentada com o propósito de que os resultados possam ser discutidos, utilizados e debatidos por outras disciplinas - inclusive a Linguística - para acrescentar conhecimento sobre a educação indígena.

Então, por que a linguagem tem um lugar central neste trabalho etnográfico sobre as escolas indígenas? Para responder a essa pergunta, expõem-se aqui alguns dados históricos e argumentos metodológicos sobre a importância da linguagem no método etnográfico, na teoria social e no estudo das escolas e da aprendizagem.

\section{Etnografia da linguagem e etnografia das escolas}

O propósito desta seção não é argumentar que estudar a linguagem é útil, mas convencer de que o estudo da linguagem permite uma aproximação especial no trabalho etnográfico nas escolas.

O argumento a desenvolver aqui é o seguinte: para entender o processo de hierarquização dos sujeitos e os modelos de escola que existem na Amazônia do Brasil e da Colômbia, bem como as consequências desses modelos nas identidades indígenas da região, é preciso começar o estudo das escolas pela linguagem. Vale a pena acrescentar que este texto não utiliza a palavra "linguagem" como sinônimo da palavra "idioma" ou "língua indígena". Utiliza a palavra linguagem no sentido da literatura antropológica: um instrumento para atuar socialmente, para criar ou produzir relações sociais. Essa definição está de acordo com a do filósofo J. L. Austin (1962) e também é compatível com o uso que a Antropologia lhe conferiu ao longo da história da disciplina.

Embora os exemplos da escola da Análise Crítica do Discurso ("ACD”, ou "CDA", em inglês) tenham sido úteis para desenvolver a metodologia nesta pesquisa, prefere-se aqui o termo "linguagem" ao termo "discurso", porque alguns autores utilizam o termo "discurso" como instrumento da comunicação para impor o poder (por exemplo, FOUCAULT, 1968, ou VAN DIJK, 2005). A pesquisa apresentada aqui, no entanto, estudou o uso da linguagem entre grupos indígenas que ocupam posições desiguais nos espaços da educação, como argumentam autores que já estudaram a 
região (ECHEVERRI, 2008; GASCHÉ, 2010; MAHECHA, 2006; GARZÓN, 2006).

A linguagem teve um papel central na literatura antropológica desde os trabalhos clássicos - e continua a ter esse papel central, às vezes de formas novas. O linguista britânico Raymond Firth afirmou, depois da morte de B. Malinowski, que a linguagem tinha uma parte central no método etnográfico de trabalho de campo graças ao trabalho de Malinowski. Malinowski entendia a linguagem como mais do que um instrumento para se aproximar dos fatos. Segundo Firth, Malinowski entendeu a linguagem como uma forma de ação social. A ideia de que as pessoas fazem coisas com as palavras já estava presente, na forma de intuição, nos trabalhos de Malinowski (FIRTH, 1974, p. 112). Nesse sentido, Firth achava semelhantes as ideias de Malinowski e as de Wittgenstein, sem sugerir que existiu ligação entre as obras desses autores. Ambos se interessavam pela função da linguagem, e não pela linguagem como reflexo da existência do pensamento do grupo (FIRTH, 1974, p. 112-113).

Essa ideia é compatível com os argumentos apresentados por Austin em seu livro How to do things with words, de 1962. O título do livro faz transparente o argumento: as pessoas não só descrevem coisas com as palavras, mas fazem coisas. Austin apresenta a teoria com exemplos muito simples: uma pessoa recebe um nome, que determina o resto da sua vida, porque alguém usou a linguagem de uma forma específica, em condições específicas; um casamento é consumado porque alguém atuou com as palavras (AUSTIN, 1962). O uso das palavras cria situações sociais, para além de apenas nomear coisas.

Mas, o que tem isso a ver com a etnografia? Para Austin, as palavras não funcionam isoladas. Elas fazem coisas quando existe a mistura certa entre contexto social e uso da palavra. Por isso, Austin fez a diferença entre happy e unhappy utterances, ou expressões "felizes" e "infelizes". As expressões felizes garantem as condições do contexto e do uso das palavras certas no resultado desejado pela pessoa que utiliza a linguagem para fazer alguma coisa. Nesse caso, a linguagem "performa" - ou, em outras palavras, permite atuar, criando relações novas. Quando não existe ligação certa entre o contexto e as palavras utilizadas, a linguagem não permite o resultado desejado. Por exemplo: se uma criança receber um 
nome de uma pessoa que não possui a posição de funcionário estadual ou de alguma autoridade social, a criança pode não ser reconhecida com esse nome (AUSTIN, 1962).

O estudo da linguagem na etnografia das escolas aproveita esses princípios. São eles: 1. As pessoas fazem coisas com as palavras, e não simplesmente descrevem coisas; e 2. Para que as pessoas façam coisas com as palavras, é preciso que exista um contexto que permita que as palavras atuem.

Para isso ser entendido no contexto da pesquisa, um exemplo pode ser útil: líderes e organizações indígenas buscam proteger as identidades e os conhecimentos indígenas entre meninos e meninas utilizando as línguas indígenas nas escolas, aproveitando direitos estabelecidos pelas Constituições do Brasil e da Colômbia. Mas, se o contexto for errado, as crianças não conseguirão aprender esses conhecimentos, mesmo que os professores indígenas façam grandes esforços, os governos nacionais e as organizações indígenas façam grandes investimentos e os acadêmicos demonstrem, na teoria, que esses conhecimentos têm valor.

Por que? Qual é o contexto que impede isso? Existem situações em que o contexto e as palavras dão certo? Podemos controlar o contexto para permitir que as palavras atuem? Quais são as palavras certas e quais as erradas? Qual é o contexto certo e qual o errado? E por que as palavras determinam o fato das crianças serem indígenas ou não, mulheres ou homens, mulheres indígenas ou homens indígenas?

\section{Identidade e linguagem}

Nesse caso, professores, crianças, lideranças indígenas, funcionários dos governos e pais de família fazem coisas que mudam ou determinam o fato das crianças nas escolas se sentirem indígenas ou não. Entre os muitos antropólogos que analisaram o tema, vale a pena lembrar o trabalho de Eidheim, que já na década de 1960 foi um dos colaboradores de Frederick Barth, na obra clássica Ethnic groups and their boundaries. Barth e seus colaboradores entenderam a identidade étnica como uma forma das pessoas se reconhecerem como pertencentes ao seu grupo, com o propósito de interagir com outras que também fazem parte desse 
grupo. Para eles, as identidades étnicas não eram criações dos grupos que aconteciam como resultado do seu isolamento desses grupos, mas, ao contrário, por causa da relação entre os grupos (BARTH, 1969). Eidheim sugeriu que as identidades étnicas existem numa posição inferior na hierarquia das relações sociais, utilizando a análise de símbolos da linguagem. Um dos símbolos mais evidentes, explicava Eidheim, é a supressão do uso da língua indígena nas situações públicas (EIDHEIM, 1969).

Segundo os estudos do discurso, que também têm se aproximado do tema, as pessoas criam relações com grupos ao utilizar uma forma de falar sobre si. Em outras palavras, as pessoas não falam de determinada forma porque fazem parte de um grupo. Pelo contrário, utilizam a linguagem com o propósito de serem reconhecidas por outros como parte de um grupo (VAN DIJK, 2005, p. 22). Um exemplo utilizado com frequência pelo linguista Teun A. Van Dijk é o fato dos falantes europeus utilizarem adjetivos positivos para falar de si, ao mesmo tempo em que utilizam adjetivos negativos para falar dos imigrantes (VAN DIJK, 1997).

A partir dessa tese, vários pesquisadores já estudaram como a linguagem determina identidades sociais. Existe um grupo de pesquisadores que estuda esse processo em categorias que descrevem a relação entre conhecimento e linguagem. Por exemplo, a antropóloga Naomi Quinn estudou a forma dos americanos construírem o que ela chama de "esquemas sociais", ou seja, representações do mundo baseadas em experiências compartilhadas sobre a vida social (QUINN, 2005).

Alguns linguistas utilizam a gramática para demonstrar as consequências do uso da linguagem em situações sociais que reduzem ou acentuam a discriminação de alguns grupos. A linguista britânica Elizabeth Morrish, por exemplo, estudou o uso dos pronomes indefinidos para demonstrar que os professores universitários têm a capacidade de aumentar ou reduzir a rejeição dos estudantes e da comunidade universitária ao utilizar they, "eles", e não we, "nós", para se referir a pessoas homossexuais (MORRISH, 2002).

West, Lazar e Kramarae explicam as formas como as pessoas utilizam conjugações ou preposições especiais para serem reconhecidas - por exemplo, "mulheres negras" -, ou para se apresentarem - "mulheres em 
situação subordinada". Outro exemplo seria o uso da voz passiva utilizado por mulheres negras dos Estados Unidos para se apresentar em uma posição subordinada ao falar sobre si (WEST, LAZAR e KRAMARAE, 2005).

Marsh e Lammers, por fim, estudam o uso da linguagem entre jovens adolescentes mexicanos para explicar a forma dos adolescentes perceberem a si mesmos como masculinos no contexto da escola. A partir de entrevistas com as crianças e com os pais, as pesquisadoras analisaram a formas como as crianças entendem a masculinidade (MARSH e LAMMERS, 2011).

\section{O que analisar na linguagem?}

Segundo alguns autores, as pesquisas qualitativas sobre a linguagem não poderiam estabelecer como fixo, de antemão, aquilo que constitui a base da observação, mas o pesquisador deve criar espaços para as estruturas da linguagem se mostrarem durante a observação (QUINN, 2005). Alguns antropólogos estudam a cognição por meio de metáforas ou "palavras-chave", porque acreditam que elas refletem "esquemas", isto é, estereótipos gerais de enxergar o mundo a partir da experiência, que estão fixos na memória e influenciam as interpretações do mundo. Ao serem compartilhados por algumas pessoas por meio da linguagem, esses esquemas definem relações culturais. Nesse tipo de pesquisa, a entrevista constitui um instrumento central, porque os "esquemas culturais" (por exemplo, "o casamento", “a democracia”, ou "a educação") não aparecem com frequência na fala cotidiana (QUINN, 2005).

Existem diferentes tipos de entrevista, e o propósito da entrevista é criar condições para que as pessoas apresentem as suas ideias de uma forma que permita observar esses esquemas culturais. Uma das mais populares formas de entrevista é a "história de vida". A história de vida é um tipo de narração a partir da experiência da pessoa entrevistada que busca entender a sociedade aproveitando o ponto de vista de um indivíduo. Originalmente, foi desenvolvida como instrumento da psicanálise, mas, com o tempo, transformou-se em instrumento da pesquisa antropológica. Nesse sentido, é diferente da biografia, porque o 
propósito, aqui, é entender as relações sociais e as mudanças históricas a partir da experiência da pessoa entrevistada, e não enfatizar a personalidade do entrevistado, nem as consequências históricas das suas decisões.

$\mathrm{Na}$ análise de várias histórias de vida de mulheres adultas que voltaram à escola após tornarem-se mães, a psicanalista Wendy Luttrell encontra estruturas de linguagem que refletem formas criadas pelas mulheres entrevistadas para se posicionar na estrutura de classe: como mulheres diferentes das professoras; como mulheres que diferenciam o "conhecimento escolar" (school smarts) do "conhecimento de rua" (street smarts); como mulheres bem sucedidas ou não; como teacher's pets ("favoritas dos professores"), entre outras (LUTTRELL, 2005).

O fato da história de vida ser um instrumento tão importante na Antropologia tem a ver com o fato de se aproveitar a análise de uma forma da linguagem que o linguista e antropólogo Dell Hymes (2004) apresenta como "universal": a narração. Hymes baseia-se em pesquisas etnolinguísticas que têm estudado a forma como a educação impede os aprendizes de argumentar a partir de fatos específicos, fazendo com que eles abandonem a narração e falem só a partir de abstrações. Esses estudos, segundo Hymes, revelam as mesmas dificuldades entre estudantes de graduação de Harvard e alunos das escolas indígenas dos Estados Unidos. Hymes leva o argumento além ao dizer que os esforços das instituições de educação por reduzir o uso da narração sugerem que ela é percebida como própria das classes baixas, embora seja um instrumento necessário do conhecimento. Dessa forma, a narração deve ser defendida como forma de conhecimento, mas também estudada pela Antropologia, pela Sociologia e pela Linguística (HYMES, 2004).

Assim, para entender as dificuldades que impõe a escola nas crianças, professores e autoridades indígenas na construção de identidades indígenas, relacionadas a ideia de conhecimento e de gênero, esta pesquisa utilizou quatro instrumentos: 1. Entrevistas orientadas pela experiência dos professores e das professoras; 2. Entrevistas orientadas pela experiência das autoridades tradicionais indígenas; 3 . Narrações das crianças sobre as suas vidas como indígenas e 4. Análise da linguagem na interação entre crianças e professores nas aulas. Este artigo apresenta os resultados da análise das entrevistas com os professores. 
Antes de apresentar os resultados dessas entrevistas, vale a pena explicar a sua importância. Elas foram inspiradas na história de vida, mas não conseguem ser verdadeiras histórias de vida, pois os professores evitaram falar de alguns aspectos das suas histórias por estarem sendo gravados. Algumas vezes, essas histórias estão relacionadas com fatos emocionalmente difíceis para os professores, principalmente nas entrevistas com mulheres. Por exemplo, com frequência, os pais rejeitam ensinar a língua indígena às meninas e, por isso, muitas professoras não falam bem a língua tradicional. Os professores indígenas, por sua vez, são contratados justamente por conhecerem a tradição e a língua indígena. Por isso, reconhecer que uma professora não fala a língua tradicional pode causar vergonha. Tratam-se, então, de entrevistas inspiradas na história de vida, mas não histórias de vida no sentido tradicional do método.

O primeiro grupo de entrevistas foi feito durante os primeiros três meses de trabalho de campo no lado colombiano do rio Solimões, com professores indígenas Murui-Muina e indígenas Ticuna, todos da Colômbia. Durante esses primeiros três meses, foram feitas, também, entrevistas com crianças indígenas Ticuna e Murui-Muina. As crianças das duas tribos pertencem à escola Francisco José de Caldas, do município de Leticia, na Colômbia. O colégio tem várias sedes em várias aldeias, que estão dentro do resguardo, e as entrevistas aconteceram em duas sedes: na sede de Virgen de las Mercedes, na aldeia Murui-Muina conhecida pelo nome de Kilómetro 11 , e na sede San Antonio, na aldeia Ticuna conhecida pelo mesmo nome.

O segundo grupo de entrevistas foi feito só com professores e professoras Ticuna do colégio Almirante Tamandaré, da aldeia de Umariaçu, no lado brasileiro do rio Solimões, localizado no município de Tabatinga. Nesse caso, os professores não exigiram uma utilidade imediata do trabalho e aceitaram a presença do pesquisador durante as aulas, bem como realizar entrevistas individuais com o pesquisador. No entanto, pediram apoio do pesquisador em oficinas organizadas pela Secretaria de Educação Estadual do Amazonas em retribuição pelo apoio à pesquisa.

Portanto, não posso sugerir que este trabalho tenha sido feito a partir de metodologias de colaboração. Sem dúvida, o propósito desta pesquisa 
é ser de utilidade para os professores indígenas no seu trabalho - e ser, também, de utilidade para as autoridades indígenas nas decisões sobre as políticas de educação indígenas. Em outras palavras, a pesquisa foi orientada por um espírito de colaboração e empatia política; os resultados buscam fortalecer pesquisas participativas, mas, por enquanto, não podem ser apresentadas dessa forma, pois foram planejadas pelo pesquisador, e não pela comunidade. Porém, ainda assim, foram transformadas pelas autoridades indígenas, pelas crianças e pelos professores e professoras. É desejável que essa experiência seja útil, no futuro, para o planejamento de métodos de pesquisa entre a comunidade e os pesquisadores.

As oficinas feitas na Colômbia foram possíveis graças ao apoio da antropóloga Daniela Botero Marulanda, que também é minha esposa. A presença de uma mulher que apoiava o meu trabalho contribuiu para que as mulheres indígenas que participaram na pesquisa sentissem confiança para falar de assuntos de gênero. As mulheres mais velhas e algumas professoras aceitaram falar de experiências femininas porque Daniela participou de várias entrevistas; e, frequentemente, embora eu fizesse as perguntas, elas respondiam falando para a minha esposa, e não para mim.

A observação da interação entre crianças e professores nas aulas foi uma observação direta, feita ao longo dos seis meses de trabalho de campo em todas as escolas que visitei. Em algumas situações, uma ou duas vezes os professores me pediram para dar uma aula ou explicar para as crianças algum tema, e eu fiz exatamente isso. No entanto, foram exceções e, por isso, não permitiram uma análise mais aprofundada.

O trabalho de campo foi realizado em duas temporadas: a primeira, entre janeiro de 2016 e agosto de 2016; a segunda, entre janeiro de 2017 e março de 2017. Durante essas temporadas, visitei as escolas das aldeias indígenas todos os dias, durante um período total de quatro meses na Colômbia e quatro meses no Brasil.

Nas páginas seguintes, apresentarei exemplos trazidos dessas entrevistas, dessas narrações e da observação direta da interação entre crianças e professores nas aulas. Os trechos das entrevistas apresentados aqui estão nas suas línguas originais, levando em conta que as 
semelhanças entre o espanhol e o português permitem ao leitor entendelas; assim, é possível manter a linguagem utilizada pelos entrevistados.

\section{"Estruturas históricas" da narração nas entrevistas com professores Murui-Muina e Ticuna da Colômbia e Ticuna do Brasil}

Argumenta-se aqui que a linguagem utilizada nas escolas indígenas é produto do esforço dos povos indígenas para articular os conhecimentos que chamamos "universais" com os conhecimentos "tradicionais". Os primeiros, necessários para se relacionar com os Estados, foram introduzidos aos povos indígenas na Colômbia e no Brasil por meio da criação de escolas nos territórios indígenas, como afirmam vários dos estudos antropológicos dos dois países (TASSINARI, 2012; D'ANGELIS, 2012; GARZÓN, 2006). O estudo da fronteira amazônica pode alimentar os esforços para resolver problemas da educação intercultural, pois a relação histórica dos povos indígenas entre eles e com os Estados e as economias nacionais permite entender os modelos atuais dessa relação.

Os processos dos Murui-Muina e dos Ticuna são, nessa perspectiva, especialmente interessantes.

Os Murui-Muina, segundo vários pesquisadores, chegaram na fronteira fugindo das formas cruéis de exploração da força de trabalho indígena no comércio e na produção da borracha desde o final do século XIX até a metade do século XX. Criaram alianças políticas, baseadas na aliança matrimonial e na incorporação de conhecimentos, com outros povos para sobreviver em um contexto caracterizado pelo que alguns autores consideram semelhante ao holocausto (PINEDA, 2000; PINEDA, 1993; ECHEVERRI, 1997).

Os Ticuna, por sua parte, afrontaram esses processos de dominação impostos pelas missões; mais tarde, o exército do Brasil e o Serviço de Proteção ao Índio deram origem aos modelos de domínio brasileiro sobre os povos indígenas. Esses modelos isolaram os Ticuna da sua relação anterior com outros povos indígenas e transformaram seus territórios (PACHECO DE OLIVEIRA, 2006 e 2010).

Durante as entrevistas, esses temas aparecem na fala dos professores indígenas, embora alguns temas apareçam com maior força do que 
outros. As narrações dos professores das escolas sobre as suas vidas como professores e como indígenas se baseavam sempre nesses temas para organizar as histórias do seu passado e as trajetórias das suas vidas dentro de uma aldeia indígena. Por ser uma base que aparece em várias narrações de professores e que organiza a narração, este artigo utiliza a expressão "estrutura histórica" para se referir a ela. A estrutura das narrações dos professores Murui-Muina sempre começava com uma referência aos parentes que chegaram na cidade de Leticia vindos do rio Putumayo até o território indígena peruano, muitos deles até a cidade de Pebas (território indígena do Povo Yagua, no rio Amazonas, no Peru). Nas narrações dos professores e professoras, os pais ou os avôs chegaram até Pebas para fugir dos comerciantes de borracha, que estavam entre os rios Putumayo e Amazonas, na Colômbia; mas, pouco depois, eram procurados por outros parentes, que conseguiram uma terra para trabalhar no território colombiano, perto da cidade de Leticia. É possível supor que esse movimento tenha acontecido entre 1948 e 1980 pela idade dos professores entrevistados, que nasceram depois da chegada dos seus pais na cidade de Leticia.

Dois exemplos podem ajudar a entender essa estrutura histórica da origem indígena nas narrações dos professores da região:

Mi papá es de ascendência Murui [Muina]. Él es de acá de la comunidad del Kilómetro 11 . Cuando mis abuelos llegaron acá [vindos do rio Putumayo], ellos vivían en la parte de atrás donde queda la maloca, aquí en el sector era todo la parte de mi abuelo, pero después se fueron y se radicaron en el Tacana, adentro... Mi papá se fue para el pueblo, entonces yo crecí vivendo en el pueblo. Entonces mi papá se metió con mi mamá que era de ascendencia brasilera, entonces mi primaria y $\mathrm{mi}$ bachillerato los hice em el Pueblo (Entrevista com a professora Maria Victoria Perez Barbosa, realizada em 9/03/2016).

Outros professores começam as suas narrações de forma semelhante:

Yo naci aquí en el resguardo, en la selva, eso me cuenta mi mamá. Y me siento muy contenta de haber nacido en donde fue nuestra primera casita... naci bajo unos platanillos que se parecen al plátano y mi mamá me dice que era ahí y que ella fue a tenerme allá... ellos [mis 
padres] eran indígenas... eran Uitoto [Murui-Muina]. Ellos tienen ascendencia de allá pero tuvieron que pasar un espacio pesado y duro porque fue en el tiempo de las caucherias. Ellos tuvieron que irse para... o fueron llevados para el Perú y del Perú un abuelo que conocia que ellos estaban por allá, cogió camino en busca de ellos. Entonces de esa manera ellos se escaparon, por asi decir, y se vinieron a Leticia (Entrevista com a professora Antonieta Vasquez, realizada em 22/04/2016 no Kilómetro 6, Leticia).

E os mesmos fatos se repetem em outras narrações:

Mi abuelo era de... en ese tiempo ese territorio pertenecía mas que todo por el Putumayo, por allá. De allá se vinieron por el desplazamiento, en ese tiempo de las caucherías y todo eso. Se vinieron para acá para Leticia y acá ya tuvieron su terreno (Entrevista com o professor Esbar Pérez, realizada em 11/03/2016 no Kilómetro 6, Leticia).

Nas narrações dos professores Ticuna, no entanto, não existe essa referência ao momento da migração desde o território dos seus avôs que, neste artigo, é chamada de "estrutura histórica". No caso dos Ticuna da Colômbia entrevistados na aldeia Ticuna de San Antonio, existe, sim, uma referência às migrações dos pais entre aldeias Ticuna do Peru, da Colômbia e do Brasil. Às vezes, narram migrações feitas até Bogotá, a capital da Colômbia, com o propósito de achar emprego, mas, ao mesmo tempo, com o propósito de voltar:

Soy muy Ticuna. Nunca conocí a mi papá. Me engendró y nunca más apareció. Hasta ahora no sé quién es mi papá. Y me siento más Ticuna. Soy muy Ticuna por mis abuelos... Mi mamá en ese tiempo trabajaba [em Bogotá]... En ese tiempo las mujeres de acá se iban a Bogotá a trabajar por vários años, mi mamá llevaba mucho tiempo allá. Como todas se enamoró y la engañaron y se devolvió para acá. Ahora yo vivo acá... crecí aquí desde los 2 años y yo soy de San Antonio, es mi origen, siempre digo que soy Ticuna [...] (Entrevista com a professora Sandra Patricia Ruiz Curico, realizada em 25/05/2016 em San Antonio de Los Lagos, Leticia). 
Neste caso, a migração para Bogotá não é apresentada como uma migração permanente, pois era um costume das mulheres Ticuna ir e trabalhar por vários anos em Bogotá para depois voltar. Em outros casos, a migração acontece dentro das aldeias Ticuna de um país até as aldeias Ticuna do país vizinho:

Nunca he salido de acá y siempre he estado trabajando acá mismo... Mis padres son de la etnia Ticuna, mi papá es proveniente del municipio de Puerto Nariño y mi mamá es de una comunidad Ticuna del Perú, pero ya muchos tiempos [sic] conviven acá, desde muy pequeño, catorce años en la comunidad... En ese tiempo la educación era muy drástica y mi papá estaba estudiando por allá y los profesores le pegaban mucho. Entonces se aburrió de eso y se escapó (Entrevista com o professor Livardo Jordán Parente, realizada em 23/05/2016 em San Antonio de Los Lagos, Leticia).

O momento de mudar de lugar, por ser um costume das mulheres (que viajavam às grandes cidades para achar emprego e voltar com dinheiro), ou por ser dentro do território indígena Ticuna, parece não ter tanta importância no caso dos Ticuna colombianos.

Essa estrutura histórica não aparece no caso dos Ticuna do Brasil. Pelo contrário: no caso deles, a narração sugere que, quando crianças, os professores não tinham consciência da importância da cultura Ticuna. Um dos professores explica essa situação assim:

No meu caso, depois de jovem [quis aprender sobre os Ticuna]. Porque meu pai próprio me contou muito isso. Falando da cultura com qualquer, falando com criança, eu nunca... como chama? Ninguém me contou, né? (Entrevista com o Professor Plínio Ramos Pereira, realizada em 15/06/2016 em Umariaçu I, Tabatinga).

Os Murui-Muina incorporam a experiência de deslocamento por causa da exploração do trabalho indígena na produção de borracha na sua experiência infantil. Os Ticuna colombianos substituem a memória da exploração da borracha por uma migração vaga entre aldeias Ticuna, ou uma migração temporária com propósitos econômicos. No caso dos Ticuna brasileiros, essa memória de migração não aparece na narração, pois, embora, durante o trabalho de campo, eu tenha observado que 
vários professores são originários do Peru, eles se percebem Ticuna por viverem dentro do território tradicional Ticuna.

Isso poderia significar que a relação histórica de cada povo com o território - ou, pelo menos, com as formas de exploração econômica nesses territórios - é incorporada à narração de forma implícita e ganha valor nas identidades dos professores. Em outras palavras, os MuruiMuina carregam aquela história como parte das suas vidas e da sua trajetória.

\section{A presença da escola na narração}

O segundo momento da estrutura histórica da narração é o momento em que os pais e os professores se tornam conscientes de que as crianças precisam ir para a escola e, por isso, decidem viver mais perto das cidades, ou enviar os filhos e as filhas para morar fora da comunidade. Um exemplo disso é a seguinte descrição:

Prácticamente ellos no vinieron especialmente aqui. Ellos se quedaron en Leticia. Ahi en Leticia hay unos lugares donde ellos vivian, sembraban sus productos, pero a raíz de que mucha gente llegaba allá ellos no querian estar como con la cantidad de gente, y muchas personas diferentes, colonos. Entonces ellos fueron subiendo. $Y$ ellos vivian entonces en el Kilómetro 5 para el aeropuerto se metieron a un lago que le dicen Urumutú y luego como que no les agradó el lugar y fueron subiendo hasta que llegaron al fondo donde yo nací prácticamente. Ahi fueron las primeras familias que llegaron y se ubicaron en ese sector. Pero ya luego, ellos viendo que ya tenían hijos y que los hijos tenían que estudiar entonces fueron saliendo. Dejando el lugar que abrieron (Entrevista com a professora Antonieta Vasquez, realizada em 22/04/2016 no Kilómetro 6, Leticia).

O desejo das famílias de ter uma escola perto para as crianças e do papel cada vez maior da escola na vida social indígena fica claro, também, na seguinte explicação:

[...] como allá no había escuela, entonces no había para poder estudiar. Y la única escuela que había era la del 
Kilómetro 6, tocaba madrugar a las 4 de la mañana y venir de allá a la 1:30pm o llegar a las 2 o 3 a pie. Entonces era muy complicado. Y en 1992 empezó otra escuela y ahí entré, por la cercania (Entrevista com o professor Esbar Pérez, realizada em 11/03/2016 no Kilómetro 6, Leticia).

Esta explicação é importante, pois aparece em relação com os processos de organização política indígena mais recentes, que não existiam nas décadas de 1960-1970:

[...] para acercarse a la carretera y para formar algo comunitario. Allá cada uno era con su chagra separado. Entonces acá si ya todos se unieron para buscar un beneficio comum (Entrevista com a professora Antonieta Vasquez, realizada em 22/04/2016 no Kilómetro 6, Leticia).

No caso dos professores Ticuna brasileiros, a presença da escola determina também a sua relação com a sociedade indígena e com os costumes dessa sociedade. A proximidade da escola cria, ao mesmo tempo, uma virada na história, que origina mais uma estrutura da narração - um terceiro momento da estrutura histórica, que pode ser chamado de "afastamento" da tradição indígena. Nesse momento, os professores experimentam uma situação de ambiguidade: os pais, mães, avôs e avós parecem se preocupar com a importância de que eles aprendam costumes tradicionais específicos segundo o gênero, embora não se preocupem com a aprendizagem da tradição indígena como uma unidade. Em outras palavras, na narração, os adultos parecem não estar preocupados que as crianças aprendam tudo da tradição, mas sim que elas aprendam as formas de trabalho que os indígenas atribuem a cada gênero.

A seguinte explicação pode servir de exemplo dessa estrutura:

Pues mi experiencia de pronto puede ser muy significativa porque yo desde muy temprana edad me separé de la familia, pero lo poco que viví lo aprendí y se me quedó ahí de pronto la escencia que yo tengo porque muy poco eso fue con mi mamá y al igual con mi papá. Yo tenia una abuela y yo me iba a dormir con ella, a acompañarla, y ella me contaba cuentos en pura lengua, a la chagra yo 
también iba a sembrar con ella, cuando ella preparaba los alimentos tradicionales. O sea, una enseñanza muy práctica. Y ella hablaba todo el tiempo en lengua y de eso yo aprendí muchas cosas. Pero ya luego cuando me fui para el internado donde terminé mi estudio, primaria y bachillerato practicamente, entonces como que eso se fue durmiendo, se fue durmiendo, pero aquello que aprendi en el poco tiempo que compartí con mi familia y con la abuelita, se me quedó ahi (Entrevista com a professora Antonieta Vasquez, realizada em 22/04/ 2016 no Kilómetro 6, Leticia).

Outras entrevistas sugerem que, embora o aprendizado das línguas entre as mulheres não fosse uma prioridade para a família, o trabalho das mulheres na agricultura tradicional e na produção de farinha era necessário entre os Murui-Muina. Ao ser perguntada sobre a aprendizagem da língua, uma das professoras respondeu:

Pues mi papá siempre fue como reacio en esa parte, él más que todo decia que la parte tradicional y la parte de la lengua, lo tenian que hablar más que todo los hombres, entonces más que todo a mi hermano, pero a mi muy poco. Y si yo le pregunto algo él me dice que eso tiene que ser en la maloca, que es el lugar sagrado, entonces él casi muy poco que me enseñó la lengua materna. Y como mi mamá no hablaba, pues menos (Entrevista com a professora Maria Victoria Perez Barbosa, realizada em 9/03/2016 no Kilómetro 6, Leticia).

Mas, ao lhe perguntar sobre a aprendizagem das formas de produção da mandioca, a mesma professora respondeu:

En el trabajo agrícola pues ahi sí trabajábamos en la chagra, sembrábamos, cosechábamos, mi papá se iba a pescar, de caceria porque en ese tiempo todavia existia la buena pesca y la buena caceria. Entonces no faltaba eso. Y como siempre lo mirábamos haciendo el mambe con el tio, el ambil y todo eso... la preparación del casabe y todas esas comidas tradicionales, pues como mi mamá no era indígena a mi mamá le tocó aprender todas esas cosas a nosotros también. Mirábamos como mi mamá rayaba la yuca, como hacía el casabe, entonces uno le ayudaba a machucar la yuca, a cernir la yuca, a pelar y hacer la fariña, porque ella lo que más hacia era fariña (Entrevista com a professora Maria Victoria Perez 
Barbosa, realizada em 9/03/2016 no Kilómetro 6, Leticia).

O caso dos professores Ticuna sugere que, entre os Ticuna, existia também um receio de ensinar as línguas tradicionais às mulheres. Uma das professoras explicou a sua relação com a língua Ticuna como uma consciência que chegou tarde:

No meu caso é assim, eu cheguei a entender a língua Ticuna já de grande, porque meus pais... minha mãe, ela é cocama, e meu pai é Ticuna. Meu pai, ele fala a língua, mas, meu pai, quando eu era criança, ele não queria me ensinar de jeito nenhum!... Porque dizia que era muito feio, né? A família da minha mãe dizia que não era para aprender. Não queriam que eu... não queriam de jeito nenhum. Mas eu... Sei lá! (Entrevista com a professora Rosinilda Almeida de Farias, realizada em 16/06/2016 em Umariaçu I, Tabatinga).

Entretanto, no caso dos homens Mururi-Muina, o afastamento da língua indígena é igualmente visível. Nesse caso, não por causa da diferença dos conhecimentos atribuídos aos gêneros masculino ou feminino, mas por causa da proximidade com a cidade:

[...] poco a poco aprendí, pero no mucho. No tuve la oportunidad de tener la lengua materna... pero me enseñaron todo lo que es la cultura, la yuca, como procesarla, cómo sembrar el ají, como hacer una casa: lo básico (Entrevista com o professor Esbar Pérez, realizada em 11/03/2016 no Kilómetro 6, Leticia).

Por outro lado, no caso dos professores Ticuna do Brasil, os homens parecem ter uma relação mais forte com a língua:

Eu estudei na cidade. Eu não sabia escrever na minha própria língua, era muito difícil, porque a minha língua própria, original, não sei escrever. Eu sei falar (Entrevista com o professor Genário Manuel Da Silva Araújo, realizada em 22/06/2016 em Umariaçu I, Tabatinga).

As entrevistas revelam mais duas estruturas que determinam os fatos narrados: um momento que pode ser chamado de "reencontro com 
o indígena" e um momento que pode ser chamado de "responsabilidade como professores". O "reencontro" é uma mudança na narração que acontece depois do "afastamento" da tradição e produz uma consciência dos conhecimentos que existiam na vida dos professores quando ainda eram crianças, fazendo-os perceber que existe um conhecimento indígena que os torna semelhantes a outras crianças indígenas. $O$ momento da "responsabilidade" acontece na virada da vida de crianças para a vida adulta, ainda cedo, na juventude.

É importante explicar que o momento do "reencontro" acontece nas narrações no espaço da escola. Professores que nasceram na década de 1970 não tiveram a mesma experiência dos professores que nasceram na década de 1950 ou 1960, os quais, segundo meus registros nos diários de campo e segundo outras pesquisas (GARZÓN, 2006), receberam castigos físicos por falar a língua indígena. Por enquanto quero enfatizar o fato dos colégios terem sido espaços de valorização de alguns aspectos da vida indígena, como as danças e as línguas, embora dirigidos ou administrados pelas igrejas e ordens religiosas.

Alguns exemplos dos "reencontros" com as línguas e danças indígenas aparecem nos seguintes trechos das entrevistas:

Y luego en el colegio habia una profesora de linguística y también fui fortaleciendo eso [o conhecimento das línguas indígenas] con ella. Pensaba yo ser una linguísta un día, me gustaba. Pero no se dió la oportunidad. Pero ahí igual he aprendido cosas... Porque en el internado donde yo estudié, Colegio Femenino Indígena Maria Auxiliadora, al simplemente usted leer "indígena" quiere decir que allí habia una riqueza de la parte tradicional. Porque allá llegaban indígenas de todo el departamento del Amazonas... Entonces allá nunca nos sometieron a esos castigos que cuentan algunos compañeros, porque ellos vivieron en los internados y que les prohibian hablar la lengua. Allá no. Además, allá trabajaban mucho las de las comunidades lauritas y yo las miraba que eran muy amigables, estaban muy pendientes de las niñas. Allá se hacian actos culturales, todo lo relacionado. Cada etnia hacia una representación ahí, y se trabajaba mucho porque teníamos la profesora de linguística y todo, o sea, ese trabajo fue bueno. De pronto por eso yo también me fui encariñando que yo queria ser linguísta y todo eso (Entrevista com a professora Antonieta Vasquez, realizada em 22/04/2016 no Kilómetro 6, Leticia). 
As danças, que, entre os Murui-Muina, têm um papel político e social (PREUSS, 1994), são centrais na formação da consciência de ser indígena durante a juventude:

Yo creo que lo que he vivido de mis abuelos, de mis padres, pues es activamente. Hacían fiestas y pues la família iba a la otra maloka y se iban a bailar y yo desde muy pequeño pues siempre me llamó la parte cultural, para ir com mis abuelos, com mis papás a las fiestas tradicionales. Ahí me fuí interesando por eso... Bailé sí, mucho. Trataba de imitar algunas canciones y ahí intentaba, pero muy poco, pero me gustaba bailar y cantar... gracias a Dios y gracias a mi abuela, desde muy pequeño he sobresalido em esa parte. Por lo menos cuando yo tenía 11 años terminé mis estudios en la comunidad y me fui para Leticia y como yo era indígena mis compañeros me decían: cuándo nos invita a la comunidad? (Entrevista com o professor Esbar Pérez, realizada em 11/03/2016 no Kilómetro 6, Leticia).

Os professores entrevistados tinham entre 35 e 42 anos no momento das entrevistas (com exceção do professor Genário Manuel Da Silva Araújo, de 55 anos). É importante levar em consideração que quase todos viveram o fim da adolescência nos últimos anos da década de 1980 e no começo de década de 1990. Isso é importante no contexto do Brasil e da Colômbia por causa do reconhecimento dos direitos dos povos indígenas que, nos dois países, acontece no final da década de 1980 . Dessa forma, as políticas oficiais de reconhecimento das sabedorias indígenas na educação nacional do Brasil e da Colômbia se desenvolveram no momento em que esses professores deixaram de ser alunos e começaram a ser professores:

Pues aquí hay padres de família que les interesa mas que todo la parte occidental, eso no es escondible. Les interesa más la parte occidental, la geometría, todos esos temas. Por eso, hacemos una salida de campo y no, ¿por qué mi hijo llegó sucio? ¿Que por qué lo llevaron a la chagra? Están perdiendo el tiempo. ¿Por qué van todos los días a la maloka a perder el tiempo? Entonces también son cosas difíciles y también lo otro es que las nuevas generaciones poco hablan la lengua materna, entonces, los que hablan son los viejos. Porque ya los de 
mi edad ya no hablan y son pocos los jóvenes que hablan (Entrevista com o professor Esbar Pérez, realizada em 11/03/2016 no Kilómetro 6, Leticia).

No entanto, no caso dos professores Ticuna brasileiros, as estruturas de reencontro com o ser indígena acontecem fora das escolas e se relacionam com a sua educação como docentes. Eles experimentaram esse reencontro sendo já pessoas adultas, à procura de uma profissão na educação:

Qual é a cultura nossa? Qual é a cultura do Ticuna? Aí eu, quando é jovem [sic], já estou trabalhando como professor, aí eu fazia pesquisa com [meu] próprio pai, aí papai me contou tudo. Da cultura Ticuna, né? Aí eu sei o dos Ticuna [sic] (Entrevista com o professor Plínio Ramos Pereira, realizada em 15/06/2016 em Umariaçu I, Tabatinga).

Entre os professores Ticuna do Brasil mais velhos, uma experiência interessante aparece, se bem que mais tarde, na vida da pessoa:

Depois que eu entrei na educação indígena, eu entendi o que era resgate da cultura do povo Ticuna. Eu tinha muito a paixão, né? A vontade de conhecer, como é que é minha origem. Então, como o colega colocou, desde 2004 escrevi na minha própria língua, fiz lançamento de música [sic]. Não assim como disse o povo, né? Assim, para publicar, mas senão para comunidade [sic]. Foi muito bom, foi aceito. Porque todas as minhas letras falam sobre respeito da nossa cultura. Porque a gente não quer perder, principalmente as crianças. Até mesmo adulto. Eles gostam. Isso vai para festival, tanto internacional quanto nacional (Entrevista com o professor Genário Manuel Da Silva Araújo, realizada em 22/06/2016 em Umariaçu I, Tabatinga).

As mulheres Ticuna do Brasil experienciam esse reencontro de forma semelhante:

Aliás, eu tinha necessidade, necessidade, né? Meu pais trabalhavam... algum dia cheguei a passar necessidade. Decidi estudar apenas para arranjar um emprego e ter o meu próprio dinheiro. Então, quando teve o ano seletivo da OGPTB [Organização Geral dos Professores Ticuna do 
Brasil], né? Eu fiz e passei e pela motivação da minha tia, né? Que também já é professora muito antiga e ela me motivou a estudar, fazer a licenciatura indígena, e quando eu cheguei lá, realmente eu vi a realidade, né? Aí foi aí, a partir daquele momento, que eu senti que, realmente, eu acho que eu tinha escolhido o lugar certo, né? A profissão que queria era trabalhar [nisso]. Mas eu fiquei triste ao mesmo tempo, porque [faz um gesto com os dedos na boca]... por causa da língua [de não saber falar a língua] (Entrevista com a professora Rosinilda Almeida de Farias, realizada em 16/06/2016 em Umariaçu I, Tabatinga).

Por isso, a partir do momento em que surge a consciência indígena, seja como adolescentes, seja como adultos, a narração deixa de ser conjugada no passado e passa do passado ao presente, até se referir ao que eles fazem hoje, da seguinte forma:

Los papás son concientes, y sobretodo los abuelos, de que la lengua materna no se tiene que perder sino que se tiene que conservar. Entonces desde años anteriores siempre se ha venido enfatizando en que la lengua materna no se debe perder pero una de las dificultades es que ni los padres de familia saben la lengua materna. Entonces los abuelos que realmente saben la lengua materna y los hijos que ya crecieron y ya tienen su famila, no saben la lengua materna como tal [sic]. Entonces, desde antes se ha venido trabajando aqui en la escuela para que los estudiantes sepan algo de la lengua materna, por lo menos decir algunas palabras de la lengua materna. Como se dice abuelo, papá, como se saluda, cosas sencillas (Entrevista com a professora Maria Victoria Perez Barbosa, realizada em 9/03/2016 no Kilómetro 6, Leticia).

É muito importante insistir na influência que a formação dentro da Organização Geral de Professores Ticuna do Brasil teve no reencontro com a cultura no caso dos professores indígenas Ticuna do Brasil. Porém, essa consciência parece surgir ainda durante a adolescência entre os Murui-Muina da Colômbia. Mas, em todos os casos, a mudança da conjugação dos sucessos representa um limite: a passagem da estrutura da narração do momento da consciência indígena ao momento da responsabilidade. 
O momento da responsabilidade traz também uma posição crítica em relação à aldeia, às autoridades e à responsabilidade com as crianças de hoje, refletindo, nessa crítica, uma consciência de gênero juntamente à consciência indígena:

[...] En el 11, la verdade es que antes las mujeres eran sometidas allá a sus cosas de mujer: cuidar el niño, ir a la chagra, todo lo que le corresponde a la mujer, al igual nosotras las mujeres indígenas. Eso si se vió, que los hombres maltrataban mucho a las mujeres, ellas eran las que practicamente sacaban adelante a sus hijos y los hombres vivian como quien dice relajados. Pues yo notaba eso desde pequeña, porque yo miraba a mi mamá y era ella la que ponía el lomo por nosotros, que éramos siempre harticos (Entrevista com a professora Antonieta Vasquez, realizada em 22/04/2016 no Kilómetro 6, Leticia).

Não parece ser muito diferente no caso das professoras Ticuna do Brasil, como sugerem as seguintes afirmações:

[...] é isso que a gente tem nossa dificuldade, né? [sic]. Muito grande na nossa comunidade. O que a gente já fala muitas vezes desde a sala de aula para elas, agora, que não conseguir [sic] ainda marido, né? Porque o número maior é esse. Elas casam muito cedo. Mais além elas pensam estudar. Mas dificuldade é grande. Porque depois vai ter filho, né? Vai ter marido. Aí começa desistir [sic]. A mulher quer estudar, então começa cair o número das meninas... [sic]. Quinze, quatorze anos já são casados, já têm mulher. Caso aconteceu comigo. Aconteceu comigo também. Eu tinha vinte anos, eu casei quando a minha esposa tinha quatorze anos... Já estão mudando, já estão entendendo o que é educação. Ou, como disse nossa tradição: quem estudar na escola é porque vai ficar preguiçoso. Não é aprender isso, não. A gente não fica preguiçosa, não. Os Ticuna desde criança a mãe adota, ensina como fazer comida, ensina como lavar prato. Tudo, né? Ensina como cuidar a casa. Então, Ticuna têm seu conhecim... [sic] Têm seu capacidade [sic]. Têm (Entrevista com o professor Genário Manuel Da Silva Araújo, realizada em 22/06/2016 em Umariaçu I, Tabatinga). 
Assim, a contradição experimentada pelos professores ao longo das suas vidas continua a existir na relação entre eles e suas próprias comunidades:

Têm pais que... a maioria dos pais aqui têm seus filhos matriculados ali na escola em São Sebastião, fora, né? [Fora da aldeia]. Lá na reunião, sempre eu estou participando. Eles falam assim: "Eu trouxe meu filho para acá [sic], porque ele não fala nada de português. Eu trouxe ele aqui para a escola do branco e eu sei que estou perdendo". O pai me disse: "Eu sei que estou perdendo. Mas meu filho tem que falar português! Porque quando ele crescer tem que arranjar um emprego, né?" [...]. Existe, sim. Mas eu acho também que é importante ele não perder a língua materna, como no meu caso... Olha, geralmente as meninas que terminaram os estudos, né? Um monte se casa, aí têm filho logo, aí não estudam mais. As mais interessadas saem para a cidade, né? Para trabalhar. A maioria viram [sic] técnico de enfermagem, ou que estudam voltadas para a educação, digamos assim, elas... elas, é muito pouco (Entrevista com a professora Rosinilda Almeida de Farias, realizada em 16/06/2016 em Umariaçu I, Tabatinga).

Em resumo, existe uma ordem de temas que se repete em várias entrevistas com diferentes professores indígenas e que reflete uma experiência semelhante e compartilhada do processo de ganhar consciência do fato de ser indígena e do lugar do gênero nesse processo. Porém, essa ordem de temas apresenta variações entre os professores Ticuna do Brasil e os professores Ticuna e Murui-Muina da Colômbia.

A ordem desses temas sugere que, na experiência desses professores, a consciência de ser indígena só começa na adolescência, e a escola tem um papel ambíguo no processo. De um lado, a escola afasta as crianças da aprendizagem da vida indígena, da língua materna e das formas tradicionais de produção. Só tarde na adolescência é que o conhecimento da língua tradicional, ou a consciência da sua existência na experiência pessoal e nas relações familiares, além da sua presença nas escolas de indígenas de outros povos da Amazônia, determinam uma nova atitude. Essa nova atitude, baseada na consciência de ser indígena, 
transforma-se em uma responsabilidade de aproveitar a condição de professor para revitalizar a cultura tradicional indígena.

Essa ordem da narração reflete uma experiência compartilhada de ser indígena. Sugiro chamar essa ordem de temas de "estrutura histórica da experiência de ser indígena". Essa estrutura segue a seguinte ordem no caso dos Murui-Muina da Colômbia: 1. As narradoras e os narradores nascem em uma família indígena onde seus antepassados fugiram da exploração do trabalho indígena no comércio da borracha (momento histórico de deslocamento territorial); 2. As narradoras e os narradores crescem em uma família que ensina os costumes indígenas de forma diferenciada para homens e mulheres (momento do aprendizado não escolar); 3. As narradoras e narradores são afastados da tradição, primeiro pela família e, depois, pelas escolas; e 4. As narradoras e os narradores vivem um reencontro com a vida indígena dentro das escolas ou na educação universitária e, ao voltar às aldeias, essa consciência se transforma em uma responsabilidade de manter e reconstruir a tradição indígena, que reflete as próprias contradições do narrador na forma de conflitos entre professor e comunidade.

No caso dos Ticuna, é possível encontrar a mesma estrutura da narração, com a exceção do momento histórico de deslocamento territorial inicial. Essa diferença da narração, que aqui é nomeada "momento histórico de deslocamento", estabelece um desafio de pesquisa importante, pois esse "momento histórico" não acontece entre os Ticuna (da Colômbia e do Brasil). Essa diferença sugere variáveis na experiência de ser indígena na Colômbia e no Brasil a partir da forma como os povos indígenas se relacionam com os Estados e as leis de cada país. Um desafio importante para o estudo dos povos indígenas na América do Sul é, em consequência, o aprofundamento no estudo comparado dessas relações.

A ordem da narração que aqui tem sido chamada de "estrutura histórica da experiência de ser indígena" poderia ser chamada, nos termos de Quinn, de "esquema cultural" e, nos termos de Hymes, de "narrativa". A expressão "estrutura" aqui utilizada não se refere a nenhuma tradição teórica da Antropologia, mas recebe o significado metafórico convencional do termo estrutura: uma base que mantém qualquer construção em pé, que segue uma ordem específica e se repete 
em qualquer construção semelhante. Nessa metáfora, a construção é o fato de se sentir indígena e de se acreditar indígena a partir da experiência diferenciada de ser mulher ou homem. Ou seja, a partir do gênero.

Essas narrações que ligam a experiência de gênero com a de ser indígena por meio da estrutura mostram que existe uma articulação entre a linguagem e a identidade indígena e de gênero, como argumentam outros autores (WEST, LAZAR e KRAMARAE, 2005).

\section{Conclusões e desafios}

As entrevistas analisadas permitem sugerir que a experiência de ser indígena passa por uma estrutura comum a muitos indígenas em diferentes países da América Latina, relacionada com uma posição ambígua entre a sociedade indígena e a sociedade não indígena. Nesse processo, é muito provável que as mudanças históricas das constituições da América Latina tenham tido um papel central. Porém, também é evidente a experiência comum dos povos indígenas no ensino fora da escola, na roça, nas malocas, na selva, na produção de farinha, ligado ao papel dos avôs e das avós e à aprendizagem da língua indígena em geral. Mesmo entre aqueles professores ou professoras que não falam a língua tradicional hoje, o fato de saber que existe uma língua indígena na sua família parece ter tido um papel central para eles se perceberem como indígenas.

A experiência de ser indígena é representada em uma estrutura histórica de quatro momentos, que refletem a ambiguidade da relação entre a sociedade nacional e a sociedade não indígena: 1. Crescer numa família e aprender tradições diferentes sendo homem ou mulher (momento do aprendizado não escolar); 2. Se afastar da tradição na família e nas escolas; 3 . Viver um reencontro com a vida indígena nas escolas; e 4. Criar uma responsabilidade de manter e reconstruir a tradição indígena, experimentando as contradições da história pessoal como contradições da comunidade. Para os Murui-Muina, essa estrutura exige um momento anterior de nascer em uma família indígena que conserva a memória de fugir do comércio da borracha (momento histórico 
de deslocamento territorial) e que revela diferenças na experiência de ser indígena na Colômbia e no Brasil.

Além dessa estrutura, o que este artigo argumenta é que a educação nos territórios indígenas que busca ser "intercultural" deve utilizar instrumentos de ensino baseados na história dos povos indígenas e nas contradições experimentadas nessa história. Cada um dos momentos da narração reflete uma contradição das escolas enquanto educação indígena diferenciada e intercultural. Essa contradição impede a articulação que, segundo Austin (1962), deveria existir entre a palavra (a mensagem comunicada) e o contexto, para que a mensagem seja efetiva. Em outras palavras, no contexto dessas contradições, ensinar as crianças a se orgulharem de ser indígenas, a defenderem as suas línguas e tradições, não as impede de continuar a perceber a vida indígena como inferior.

A primeira de tais contradições é lutar pela defesa da cultura e, ao mesmo tempo, tentar afastar as crianças da tradição para que aprendam as línguas e os conhecimentos dominantes (português e espanhol). Segundo Eidheim (1969), os povos indígenas que se encontram em situação de subordinação ocultam o uso da língua indígena em situações públicas. A experiência das professoras com famílias que evitavam lhes ensinar as línguas indígenas é evidência dessa tendência na região do Amazonas. O uso da língua é uma forma de ação: reduzir o uso da língua aos espaços privados e evitar o seu uso na escola é uma forma de aceitar a subordinação da sociedade indígena pela sociedade nacional. É importante levar em conta que, embora as Constituições da Colômbia e do Brasil reconheçam o direito ao uso dessas línguas, na realidade das aldeias ainda existe o medo de que as crianças aprendam as línguas indígenas. As experiências narradas aqui são evidência desse medo.

A segunda dessas contradições é o fato das famílias ensinarem às crianças costumes e conhecimentos indígenas, mas colocarem sobre a escola a responsabilidade de preparar as crianças para sair da vida da aldeia e encontrar emprego nas cidades. De novo, a experiência indígena é contraditória porque exige a cultura indígena na vida privada da família; a escola, porém, é percebida como pública e, por isso, alheia às tradições, embora se exija dos professores que ensinem a cultura. Essa contradição é também resultado de causas históricas: a lei muda, as escolas mudam, 
mas as famílias continuam a ter medo de que suas crianças saibam muito das culturas indígenas e não o suficiente da vida brasileira ou colombiana.

A terceira contradição é colocar nos professores toda a responsabilidade de fazer com que as crianças se reencontrem com o orgulho de ser indígena quando a sociedade retirou parte dessa experiência dos professores quando eles próprios eram crianças. Um bom exemplo disso é a situação das professoras e dos professores que só entendem, mas não falam a língua tradicional. Eles aprenderam quando crianças que isso era "feio" (para utilizar a expressão de alguns deles), mas, agora, eles são julgados por não saber falar. O mesmo acontece com os professores Murui-Muina da Colômbia que levam as crianças para trabalhar na roça, mas afrontam a rejeição dos pais que não querem que seus professores substituam o trabalho na sala de aula pelo trabalho na roça.

No entanto, os professores tentam reverter essa ausência da experiência indígena, insistindo no momento de se reconhecer como indígena com orgulho durante a juventude. Fazem isso como uma forma de atuar frente às contradições da comunidade. Isso reflete a tese do uso da linguagem como instrumento político da identidade, argumentada por Eidheim (1969), de um lado, e Van Dijk (2005), do outro.

A quarta contradição é a procura por resolver as dificuldades da educação dentro dos limites da escola. A solução desses problemas não pode acontecer só no espaço da escola, pois, como mostram as experiências dos professores, reflete-se também na relação entre a escola e a aldeia: os professores levam as crianças para a roça e os pais rejeitam essa forma de ensino, os professores ensinam a língua indígena e os pais buscam levar as suas crianças para escolas na cidade.

A solução desses problemas deve ser resultado de uma consciência de cada povo da sua situação histórica. Por isso, o ensino da história de cada povo, segundo a perspectiva de cada povo, na língua de cada povo, dentro das escolas indígenas é central para a educação intercultural.

Dessa forma, um dos maiores desafios da pesquisa sobre a educação indígena é entender melhor a relação entre a experiência histórica dos povos indígenas na economia da América Latina e as identidades coletivas dos grupos e indivíduos. Essa experiência histórica, como mostram os depoimentos dos professores analisados aqui, faz 
parte de uma hierarquia desigual entre os conhecimentos indígenas e os conhecimentos "universais", que devemos mudar.

\section{Referências bibliográficas}

AUSTIN, J. L. How to do things with words: the William James Lectures, delivered at Harvard University in 1955. London: Oxford University Press, 1962.

BARTH, F. (Org.). Ethnic groups and boundaries. Boston, Masachussets: Little Brown and Company, 1969.

CASTILLO, E.; ROJAS, A. Educar a los otros: Estado, políticas educativas y diferencia cultural en Colombia. Popayán: Editorial Universidad del Cauca, 2005.

D'ANGELIS, W. D. R. Aprisionando Sonhos: a educação escolar indígena no Brasil. Campinas: Curt Nimuendajú Editora, 2012.

ECHEVERRI, J. A. The people of the center of the world: a study in culture, history and orality in the Colombian Amazon. 1997. 318 f. Tese (Doutorado em Antropologia) Faculty of Political and Social Sciences at the New School for Social Research, [1997].

. ¿De chagrera a secretaria? Balance de algunas acciones en etnoeducación en el Amazonas colombiano. In: BERTLEY, M.; GASCHÉ, J. (Orgs.). Educando en la diversidad: investigaciones y experiencias educativas interculturales y bilingûes. Quito: Abya-Yala, 2008. p. 135-166.

EIDHEIM, H. When ethnic Identity is a social stigma. In: BARTH, F. (Org.). Ethnic groups and boundaries. Boston: Little Brown and Company, 1969. p. 39-57.

FIRTH, R. El análisis etnográfico y el lenguaje en la obra de Malinowski. In: FIRT, R. et al (Org.). Hombre y cultura en la obra de Bronislaw Malinowski. Buenos Aires: Siglo XXI Editores, 1974 [1957]. p. 111-140.

FOUCAULT, M. Las palabras y las cosas: una arqueología de las ciencias humanas. Buenos Aires: Siglo XXI, 1968.

GARZÓN, O. Educación, Escuela y Territorio en las regiones de los ríos Medio y Bajo Caquetá, Mirití y Bajo Apaporis. In: GARZÓN, O. (Org.). Educación, Escuela y Territorio en la Amazonía Colombiana. Bogotá: Fundación Gaia Amazonas, 2006. p. 21-86.

GASCHÉ, J. De hablar de educación intercultural a hacerla. Mundo Amazónico, Leticia, Colombia, v. 1, p. 111-134, 2010. 
GOBBI, I. O que os livros didáticos dizem sobre os povos indígenas? In: TASSINARI, A. M. I. et al (Org.). Educação indígena: noções nativas de infância, aprendizagem e escolarização. Florianópolis: Editorial da UFSC, 2012. p. 223-244.

HYMES, D. Ethnography, Linguistics, Narrative inequality: Toward an Understanding of Voice. Bristol, PA: Taylor \& Francis Inc, 2004 [1996].

LUTTRELL, W. Good enough methods for life-story analysis. In: QUINN, N. Finding Culture in talk: a collection of methods. New York. Palgrave Macmillan, 2005 p. 243268.

MAHECHA, D. Leer y escribir "Brujería de Blanco": los procesos de escolarización en el Bajo Apaporis. In: GARZÓN, O. (Org.), Educación, Escuela y Territorio en la Amazonía Colombiana. Bogotá: Fundación Gaia Amazonas, 2006.

MARSH, J.; LAMMERS, J. C. Figured Worlds and Discourses of Masculinity: Being a Boy in a Literacy Classroom. In: ROGERS, R. (Org.). An introduction to critical discourse analysis in education. New York: Routledge, 2011. p. 93-116.

MORRISH, E. The case of the indefinite pronoun: discourse and the concealment of lesbian identity in class. In: LITOSSELITI, L.; SUNDERLAND, J. (Org.). Gender Identity and discourse analysis. Nottingham: Trent University, 2002. p. 177-192.

NASCIMENTO, R. N. F. Interculturalidade e Educação escolar indígena em Roraima: da normatização à prática cotidiana. 2014. 264 f. Tese (Doutorado em Antropologia) - Programa de Pós-graduação em Antropologia da Universidade Federal de Pernambuco, [2014].

PACHECO DE OLIVEIRA, J. A presença indígena na formação do Brasil. Brasília: SECAD/UNESCO, 2006.

Acción indigenista y utopía milenarista: desvíos y caminos de un proceso de constitución territorial entre los Ticuna. In: DEL CAIRO, C.; CHAVEZ, M. (Org.). Perspectivas antropológicas sobre la Amazonía contemporánea. Bogotá: Pontificia Universidad Javeriana, 2010. p. 51-79.

PINEDA, R. Holocausto en el Amazonas: una historia social de la Casa Arana. Bogotá: Planeta, 2000.

Etnocidio, proyectos de resistencia y cambio socio-cultural en el bajo Caquetá Putumayo. In: CORREA, F. (Org.). Encrucijadas de Colombia Amerindia. Bogotá: ICAN-COLCIENCIAS, 1993. p. 183-202.

PREUSS, T. Religión y mitología de los Uitoto: Primera Parte. Bogotá: Universidad Nacional de Colombia, 1994. 
QUINN, N. How to reconstruct schemas people use, from what they say. In:

Finding Culture in talk: a collection of methods. New York: Palgrave Macmillan, 2005. p. 35-84.

TASSINARI, A. M. I. A sociedade contra a escola. In: TASSINARI, A. M. I.; GRANDO, B. S.; ALBUQUERQUE, M. A. (Org.). Educação indígena: noções nativas de infância, aprendizagem e escolarização. Florianópolis: Editorial da UFSC, 2012. p. 115-144.

VAN DIJK, T. A. El discurso como interacción en la sociedad. In: . (Org.). El discurso como interación social: estudios sobre el discurso II una introducción multidisciplinaria. Barcelona: Gedisa Editorial, 2005.

Racismo y análisis crítico de los medios. Barcelona: Paidós, 1997.

WEST, C.; LAZAR, M.; KRAMARAE, C. El género en el discurso. In: . (Org.). El discurso como interación social: estudios sobre el discurso II una introducción multidisciplinaria. Barcelona: Gedisa Editorial, 2005.

\section{Entrevistas}

1. Professora Maria Victoria Perez Barbosa, nove de março de 2016, Colégio Francisco José de Caldas, sede Virgen de las Mercedes, Kilómetro 6, Leticia, Colômbia.

2. Professora Antonieta Vasquez, 22 de abril de 2016, Colégio Francisco José de Caldas, sede Virgen de las Mercedes, Kilómetro 6, Leticia, Colômbia.

3. Professor Esbar Pérez, 11 de março de 2016, Colégio Francisco José de Caldas, sede Virgen de las Mercedes, Kilómetro 6, Leticia, Colômbia.

4. Professora Sandra Patricia Ruiz Curico, 25 de maio de 2016, Colégio Francisco José de Caldas, sede San Antonio de Los Lagos, Leticia, Colômbia.

5. Professor Livardo Jordán Parente, 23 de março de 2016, Colégio Francisco José de Caldas, sede San Antonio de Los Lagos, Leticia, Colômbia.

6. Professor Plínio Ramos Pereira, 15 de junho de 2016, Colégio Oi Tchurüne, Umariaçu I, Tabatinga, Brasil.

7. Professor Genário Manuel Da Silva Araújo, 22 de junho de 2016, Colégio Almirante Tamandaré, Umariaçu I, Tabatinga, Brasil.

8. Professora Rosinilda Almeida de Farias, 16 de junho de 2016, Colégio Oi Tchurüne, Umariaçu I, Tabatinga, Brasil. 
Mauricio Caviedes - É possível fazer uma etnografia das escolas?

Recebido em: 12/05/2017 * Aprovado em: 21/06/2017 * Publicado em: 31/12/2017

Espaço Ameríndio, Porto Alegre, v. 11, n. 2, p. 14-47, jul./dez. 2017. 